\title{
PARTICIPAÇÃO COMUNITÁRIA NO PLANEJAMENTO VIÁRIO DE ALGUNS BAIRROS DA CIDADE DE AMERICANA/SP ${ }^{1}$
}

\author{
Luzia Ferreira da Silva ${ }^{1,2}$, Andrea Volpe-Filik ${ }^{3}$, Ana Maria Liner Pereira Lima ${ }^{4}$, Demóstenes \\ Ferreira da Silva Filho ${ }^{5}$
}

\begin{abstract}
RESUMO
O envolvimento da comunidade é um elemento fundamental para maior êxito no planejamento da arborização urbana. $O$ presente trabalho teve os objetivos de, junto à população local, escolher espécies para plantio nas calçadas e colaborar no envolvimento das pessoas em solucionar os freqüentes problemas relacionados à educação ambiental. Na primeira fase constataram-se 2.551 indivíduos plantados, 76 espécies e 1.314 locais com potenciais para plantio; com base nos dados estudados, foram selecionadas 26 espécies potenciais a serem votadas pela população dos bairros. Na segunda fase realizaram-se entrevistas, com aplicação de questionário aos moradores, que não tinham plantas nas calçadas. O questionário era acompanhado de pranchas com fotos das espécies selecionadas e características da rua em questão. Dos moradores entrevistados, 70,04\% já tiveram uma árvore plantada na calçada e, $79,76 \%$ rejeitaram o plantio em frente às suas casas. Mais da metade dos moradores entrevistados (61,13\%) desconhece o responsável pela arborização urbana e a maioria $(67,21 \%)$ não reconhece os benefícios que a calçada verde pode fornecer. A ordem de preferência foi de 54,49\% para arbustos, 29,55\% para árvores, sendo que 8,91\% não opinaram e 4,05\% disseram não gostar de planta alguma. As espécies, Stifftia crysantha Mikan e, Lagerstroemia indica L. foram as mais votadas pelos moradores.
\end{abstract}

Palavras-chave: participação comunitária, arborização viária e árvores com flor

\footnotetext{
${ }^{1}$ Parte da Dissertação de Mestrado em Agronomia apresentada pela autora à ESALQ/USP, bolsista CNPq.

2 Enga . Agrônoma, doutoranda do Departamento de Produção Vegetal ESALQ/USP, Ifsilva@esalq.usp.br
3 Enga. Agrônoma, doutoranda do Departamento de Produção Vegetal ESALQ/USP, avfilik@esalq.usp.br

${ }^{4}$ Eng $^{\mathrm{a}}$. Agrônoma, $\operatorname{Prof}^{\mathrm{a}} \mathrm{Dr}^{\mathrm{a}}$. do Departamento de Produção Vegetal, ESALQ/USP, amlplima@esaql.usp.br.

5 Eng. Agrônomo, Prof. Dr. do Departamento de Ciências Florestais, ESALQ/USP, dfsilva@esaql.sup.br.
} 


\title{
COMMUNITARIAN PARTICIPATION AT URBAN PLANNING OF SOME DISTRICTS OF THE MUNICIPALITY OF AMERICANA/SP, BRAZIL
}

\begin{abstract}
The community involvement is a fundamental element for great successes at planning of urban forestry. This worked intended, together with the locals, to select plant species for pavements and to involve the in looking for solutions of frequent problems related to environmental education. The first phase found 2,551 trees planted, 76 species and 1,314 potential sites for planting; based on the data collected, 26 species were considered with potential for popular polling in the districts. In the second phase, interviews were made with a questionnaire for the dwellers that did not have plants in their pavements. The questionnaire came along boards with pictures of the selected species and the characteristics of their streets. Of the dwellers interviewed, $70.04 \%$ already had a tree in the pavement and $79.76 \%$ rejected a tree in front of their houses. More than a half of the dwellers interviewed $(61.13 \%)$ did not know the responsible for urban forestry and the majority of them (67.21\%) did not know the benefits of having a green in their pavement. The preference for shrubs was $54.49 \%$ and $29.55 \%$ for trees. The species Stifftia crysantha Mikan e Lagerstroemia indica L. won the preferences of the dwellers in the poll.
\end{abstract}

Key-words: communitarian participation; urban forestry; flowering trees 


\section{INTRODUÇÃO}

A comunidade tem função primordial no sucesso do planejamento da arborização urbana e sua participação constitui uma prática recomendável, como forma de educação ambiental. Tal educação implica, não somente em provocar mudanças de atitudes e comportamentos relacionados à arborização urbana, mas, em aproveitá-los como oportunidades potenciais, geradoras de transformação de posturas contrárias ao plantio de árvores.

Diante do atual paradigma dos órgãos públicos em buscar novas parcerias para melhorar o desenvolvimento sustentável das cidades, a participação da comunidade vem nortear esses desafios para os próximos séculos.

Segundo Paiva e Gonçalves (2002), o plantio comunitário envolve duas questões: os órgãos públicos não podem arcar, isoladamente, com todas as despesas e o plantio cria vínculo social entre a comunidade e a árvore, estabelecendo uma dependência e continuidade, que vão além de partidos e mandatos políticos.

De acordo com Kuchelmeister e Braatz (1993), é possível identificar a participação da comunidade por meio de contatos de grupos da comunidade, de entrevistas com as pessoas e negociações com os setores privados para viabilização econômica da arborização urbana.

Desta forma, este trabalho teve o objetivo de envolver a comunidade, explicando os benefícios de se plantar árvores, bem como apontar sugestões para mitigar os obstáculos em relação à construção e ao espaço, além de conscientizar a comunidade sobre a necessidade da preservação da vegetação e os cuidados que ela requer.

\section{MATERIAL E MÉTODOS}

A pesquisa foi realizada nos dois bairros mais populosos do município de Americana, Estado de São Paulo, e foi dividida em duas fases.

$\mathrm{Na}$ primeira fase, foi feito um levantamento de todas as árvores plantadas nas calçadas, de ruas com comprimento menor que 800 metros, de 800 a 1.500 metros e maior que 1.500 metros, avaliando-se:

1. calçada (largura em metros);

2. rua (largura em metros, declividade, sombreamento);

3. presença de fiação elétrica;

4. presença de encanamento;

5. calçada com cova vazia e árvores mortas e tocos;

6. calçada com possibilidade de plantio. 
Após o levantamento destes dados, foi realizado um estudo com as espécies que poderiam ser indicadas para o plantio no local, considerando as condições de espaço, declividade da rua, rede elétrica, encanamento e as características da espécie (caducifólia, semicaducifólia, perenifólia, origem, floração e frutificação). Foram escolhidas 26 espécies, variando entre arbustos e árvores de pequeno e grande porte.

Tabela 1 - Espécies indicadas para o plantio nas ruas dos bairros de Americana/SP, considerando nome científico, nome popular, origem (nativa $(\mathrm{N})$ e exótica $(\mathrm{E})$ ), abscisão foliar (perenifólia $(\mathrm{P})$, caducifólia $(\mathrm{C})$ e semicaducifólia $(\mathrm{SC})$ ), período de floração e de frutificação

\begin{tabular}{|c|c|c|c|c|c|}
\hline Nome Popular & Nome Científico & Origem & $\begin{array}{l}\text { Abscisão } \\
\text { Foliar }\end{array}$ & Floração & Frutificação \\
\hline Alectrion & Alectryon tomentosum Radlk. & $\mathrm{E}$ & $\mathrm{P}$ & Out - Nov & Mar - Mai \\
\hline Babosa -branca & Cordia superba Cham. & $\mathrm{N}$ & SC & Out - Fev & Set - Nov \\
\hline Canela da índia & Cinammomum zeylanicum Ness. & $E$ & $\mathrm{P}$ & Jul - Ago & Set - Out \\
\hline Canforeira & $\begin{array}{l}\text { Cinammomum camphora (L.) Ness } \\
\text { Sebern }\end{array}$ & $E$ & $\mathrm{P}$ & Out - Dez & Jan - Mar \\
\hline Carrapateira & Metrodorea nigra St. Hil. & $\mathrm{N}$ & $\mathrm{P}$ & Set - Nov & Mar - Abr \\
\hline Carrapeta & Trichilia hirta L. & $\mathrm{N}$ & SC & Out - Nov & Mai - Jul \\
\hline Cereja do Rio Grande & Eugenia involucrata D. C. & $\mathrm{N}$ & $\mathrm{C}$ & Set - Nov & Out -Dez \\
\hline Chal chal & Allophyllus edulis (A. St. Hil.) & $\mathrm{N}$ & $\mathrm{P}$ & Set - Nov & Nov - Dez \\
\hline Coração de negro & Poecilanthe parviflora Benth & $\mathrm{N}$ & $\mathrm{P}$ & Out - Nov & Jun -Jul \\
\hline Dois irmãos & Conofaryngia crassa Stapf. & $E$ & SC & Ano todo & Ano todo \\
\hline Erva mate & Ilex paraguariensis St. Hil. & $\mathrm{N}$ & $P$ & Out -Dez & Jan - Mar \\
\hline Espinheira santa & Maytenus ilicifolia Mart. Ex. Reiss. & $\mathrm{N}$ & $\mathrm{P}$ & Ago - Out & Jan - Mar \\
\hline Espirradeira & Nerium oleander $\mathrm{L}$. & $E$ & $\mathrm{P}$ & Set - Mar & Mai - Jul \\
\hline$\overline{\text { Estífia }}$ & Stifftia crysantha Mikan & $\mathrm{N}$ & $P$ & Jul - Set & Set - Nov \\
\hline Geniparana & Gustavia augusta L. & $\mathrm{N}$ & $\mathrm{P}$ & Out - Dez & Mar - Mai \\
\hline Grevílea - anã & Grevilea banksii R. Br. & $E$ & $\mathrm{P}$ & Jan - Dez & Ano todo \\
\hline Guaçatonga & Casearia sylvestris Sw. & $\mathrm{N}$ & $\mathrm{P}$ & Jun - Ago & Set - Nov \\
\hline Guaxupita & Esenbeckia grandiflora Mart. & $\mathrm{N}$ & $\mathrm{P}$ & Nov-Jan & Jun - Ago \\
\hline Jasmim do campo & Peschiera fuchsiaefolia Miers. & $\mathrm{N}$ & $\mathrm{P}$ & Out -Nov & Mai - Jun \\
\hline João mole & $\begin{array}{l}\text { Guapira graciliflora (Mart. Ex. J. A . } \\
\text { Schimidt) Lundel }\end{array}$ & $\mathrm{N}$ & $P$ & Ago - Set & Out -Nov \\
\hline Manduirana & $\begin{array}{l}\text { Senna macranthera (Collad.) Irwin et } \\
\text { Barn. }\end{array}$ & $\mathrm{N}$ & $P$ & Dez - Abr & Jul - Ago \\
\hline$\overline{\text { Oiti }}$ & Licania tomentosa (Benth) Fritsch & $\mathrm{N}$ & $\mathrm{P}$ & Jun - Ago & Jan -Mar \\
\hline Pau - cigarra & Senna multijuga (Rich.) Irwin et Barn. & $\mathrm{N}$ & $\mathrm{C}$ & Dez-Abr & Abr-Jun \\
\hline Pitosporo incenso & Pittosporum undulatum Vent. & $\mathrm{E}$ & $\mathrm{P}$ & Ago -Set & Dez - Jan \\
\hline
\end{tabular}




\begin{tabular}{llllll}
\hline Rededá - anão & Lagerstroemia indica L. & E & C & Dez -Mar & Abr -Jun \\
\hline Tingui & Dictyoloma vandellianum A. Juss. & N & P & Fev - Abr & Jul - Ago \\
\hline
\end{tabular}

Fonte: LORENZI et al. (1992, 1998, 2003)

As espécies, Lagerstroemia indica, Neriun oleander e Licania tomentosa, já se encontravam plantadas nas calçadas. As demais foram indicadas com o objetivo de mostrar aos moradores, que existem espécies não comuns ao seu cotidiano e que podem apresentar potencial para arborização viária.

$\mathrm{Na}$ segunda fase da pesquisa, foi aplicado um questionário para os moradores que não tinham plantas nas calçadas. O questionário constava de perguntas simples e objetivas, buscando conhecer a opinião dos moradores sobre arborização urbana e investigar o motivo de não ter mais árvores plantadas em sua calçada.

As perguntas foram as seguintes:

1) Você já plantou uma árvore em frente a sua casa? ( )Sim ( )Não

2) Gostaria de plantar? ( )Sim ( )Não

3) Qual tipo de planta você gosta?

( )arbustos ( )árvores ( )tanto faz ( )nenhuma

4) A calçada com grama (calçada verde $-50 \%$ ) traz benefícios? ( )Sim ( )Não

5) Você sabe quem é o responsável pela arborização da cidade? ( )Sim ( )Não

6) Em qual dessas árvores você votaria?

O questionário foi acompanhando de pranchas, contendo as fotos das espécies indicadas para cada rua. Não foi aplicado questionário nas ruas menores que 800 metros. Em cada prancha (Figura 1) constava o nome da rua, seu comprimento (de 800 a 1.500m e maior que $1.500 \mathrm{~m}$ ), sua largura e da calçada correspondente; o bairro; o potencial de plantio; observações (declividade e sombreamento); presença ou não de fiação elétrica e o nome científico e popular de cada espécie.

As fotos das espécies indicadas tinham o mesmo tamanho e padrão para não haver influência na escolha. Verificou-se que, em algumas ruas, existiam espécies que apresentavam características de interesse para a arborização viária; para aumentar a porcentagem destas espécies, elas foram incluídas na listagem a ser votada.

As ruas de 800 a 1.500 metros, foram oferecidas três espécies aos moradores, sendo selecionadas as duas mais votadas para o plantio; já para as ruas maiores que 1.500 metros, ofereceram-se quatro para seleção de três. O processo de plantio das espécies mais votadas caberá à Prefeitura Municipal, que deverá arcar com as atividades ou delegálas às empresas interessadas. 


\section{Prancha no 1}

Rua Adelmar Tavares Bairro AZ II

Possibilidade de plantio: 29

Largura : Calçada - 1,95m

$$
\text { Rua }-7,80 \mathrm{~m}
$$

Comprimento da rua: entre 800 a $1500 m$ - 3 espécies

Obs. Sol de manhã, declive

\section{Fiação}
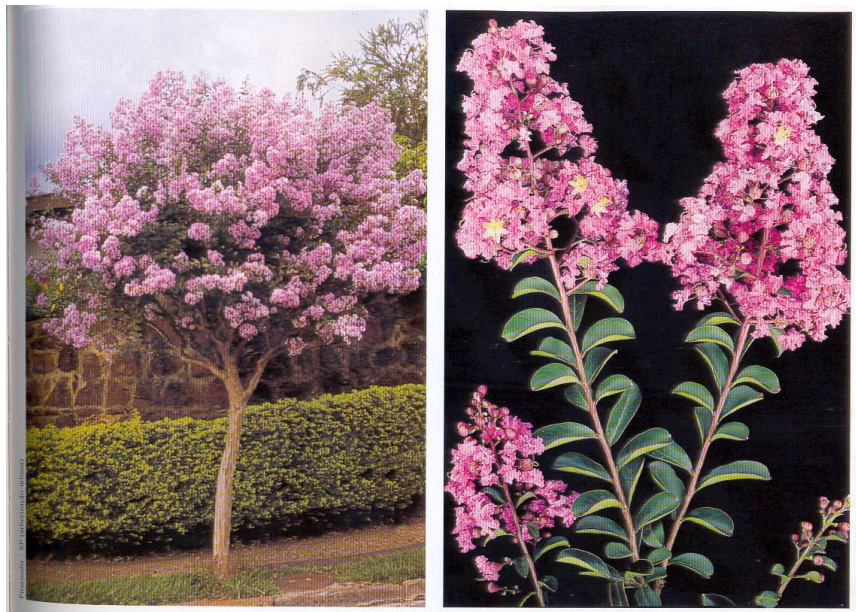

Lagerstroemia indica (Resedá anão)

\section{Sem fiação}

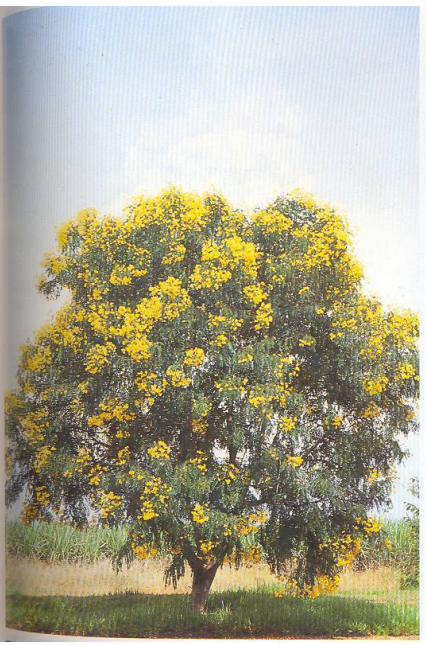

Senna multijuga (Rich.) Irwin et Barn.

(Pau - cigarra)
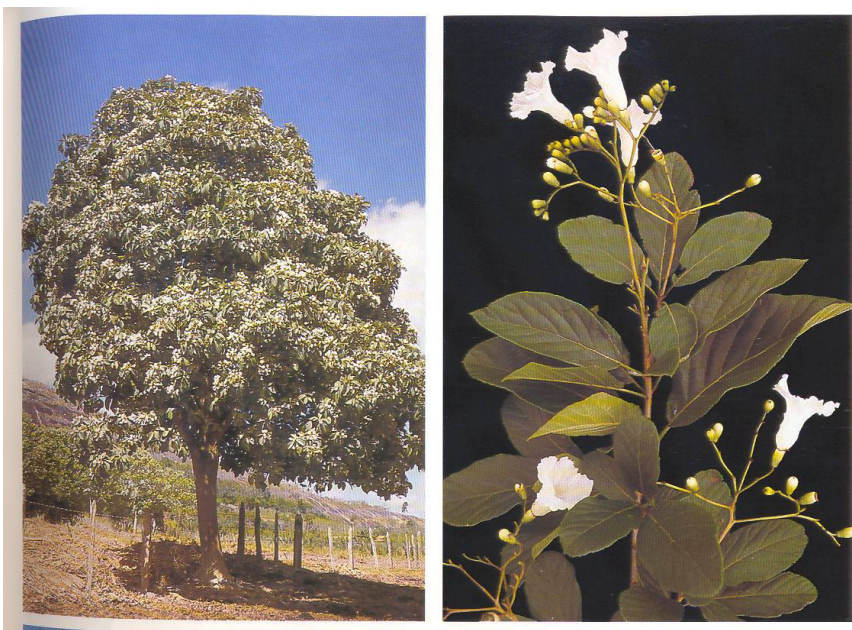

Cordia Superba Cham.

(Babosa - branca)

Figura 1 - Prancha das espécies mostrada aos moradores, específica para cada rua, nos bairros analisados de Americana/SP 


\section{RESULTADOS E DISCUSSÃO}

Foram observados 2.551 indivíduos plantados nas calçadas, 181 covas vazias, 89 árvores mortas ou tocos e 1.314 lugares com potencial de plantio, em todas as ruas, inclusive, aquelas menores que 800 metros. Os bairros apresentaram-se arborizados, porém verificou-se, ainda, a existência de espaços, com possibilidade de plantio de 1.314 indivíduos, os quais se fossem plantados, promoveriam considerável melhoria para a arborização urbana local.

Foram encontradas 485 casas que não tinham árvores nas calçadas. Destas, foram entrevistados 247 moradores, sendo um de cada casa; 162 casas encontraram-se sem moradores e 55 não quiseram atender. Além disso, 15 casas estavam com material de construção espalhados pela calçada e 6 já tinham feito o pedido de muda (Tabela 2).

Tabela 2 - Moradores entrevistados nos bairros de Americana/SP

\begin{tabular}{lcc}
\hline Descrição & Quantidade & Porcentagem (\%) \\
\hline Moradores entrevistados & 247 & 50,93 \\
Casas sem moradores & 162 & 33,40 \\
Moradores que não quiseram responder & 55 & 11,34 \\
Casas em construção & 15 & 3,09 \\
Moradores que já fizeram pedido de muda & 6 & 1,24 \\
Total & 485 & 100 \\
\hline
\end{tabular}

Das pessoas entrevistadas, 70,04\% já tiveram uma árvore plantada na calçada e $79,76 \%$ não quiseram plantar (Tabela 3 ).

Mais da metade dos moradores $(61,13 \%)$ desconhece quem é o responsável pelo plantio e manutenção das árvores; e o restante $(38,87 \%)$ respondeu que é a prefeitura $(94,79 \%)$, o próprio morador (3,12\%) ou uma pessoa contratada (2,08\%) (Tabela 3 e 4$)$.

A rádio comunitária local comunicou à população sobre a pesquisa e fez alerta sobre a importância da participação dos moradores nas entrevistas. Contudo, houve alto número de residências, encontradas sem o morador. Desse modo, a entrevista se estendeu por vários horários e dias, mas não ultrapassou três meses. 
Tabela 3 - Resultado, em porcentagem, da opinião dos moradores dos bairros de Americana/SP, sobre arborização urbana

\begin{tabular}{lcccc}
\hline Descrição & Sim (\%) & Não (\%) & Total (\%) \\
\hline $\begin{array}{l}\text { Moradores que já tiveram plantas } \\
\text { calçadas }\end{array}$ & & & 100 \\
Moradores que gostariam de plantar & 20,24 & 79,76 & 100 \\
Benefícios da calçada com grama & 32,79 & 67,21 & 100 \\
Conhecem o responsável pela arborização & 38,87 & 61,13 & 100 \\
\hline
\end{tabular}

Tabela 4 - Opinião dos moradores a respeito do responsável pela arborização na cidade de Americana/SP

\begin{tabular}{lll}
\hline Descrição & Quantidade & Porcentagem (\%) \\
\hline Prefeitura municipal & 91 & 94,79 \\
O próprio morador & 3 & 3,13 \\
Contratado pelo morador & 2 & 2,08 \\
Total & 96 & 100 \\
\hline
\end{tabular}

O desinteresse dos moradores em se plantar uma árvore em frente à sua casa evidencia que a relação entre as pessoas e a natureza tem sido afetada pela mudança de valores sociais, conforme enfoca Konynendiyk (2000).

A maioria dos moradores $(67,21 \%)$, na tabela 3, não percebeu os benefícios que as calçadas verdes fornecem como captação e infiltração de água e somente apontaram problemas, tais como, proliferação de insetos e sujeira de animais; entretanto, os moradores que opinaram pelos benefícios (32,79\%), são pessoas que reconhecem a importância do verde no meio urbano.

O desconhecimento dos moradores, sobre o responsável pela arborização urbana na cidade, é um problema que reflete na paisagem. A função do responsável repercute nos moradores de duas maneiras: a instrução do manejo adequado e a aplicação da sanção aos infratores. Nesse sentido, as pessoas plantam sem conhecimento sobre o tipo de espécie mais adequada; além de preparar uma cova insuficiente e utilizar uma muda de altura imprópria. Ainda mais grave, supõem que podem suprimir a árvore quando bem quiserem.

Os motivos que desestimularam as pessoas a não plantarem mais árvores nas calçadas foram muitos, porém, os destaques mais relevantes foram à fiação elétrica, casa alugada e danos em calçadas (Tabela 5). 
Tabela 5 - Opinião dos moradores que recusaram o plantio de árvores nos bairros de Americana/SP

\begin{tabular}{lll}
\hline Descrição & Quantidade & Porcentagem (\%) \\
\hline Não opinaram & 101 & 51,27 \\
Tem fiação elétrica & 40 & 20,30 \\
Casa alugada & 32 & 16,24 \\
Danos à calçada & 20 & 10,15 \\
Casa vendida & 2 & 1,02 \\
Arrumar a posição da garagem & 1 & 0,51 \\
Calçada estreita & 1 & 0,51 \\
Total & 197 & 100 \\
\hline
\end{tabular}

Ao escolher uma árvore, os moradores comentaram sobre outras possíveis preocupações, por exemplo, futuras despesas com podas para minimizar danos à fiação elétrica; morosidade do poder público, em relação aos pedidos de podas e substituição de árvores e, ainda, profissionais pouco capacitados atuando no setor.

A poda, quando necessária, deve ser bem planejada para reverter diretamente em economia de recursos, tanto para os órgãos públicos, como para os moradores. Para Milano e Dalcin (2000), as podas das árvores, juntamente com o plantio, são práticas de interatividade com a população, e conseqüentemente, com o poder público e a mídia.

Dentre os que não opinaram $(51,27 \%)$ na Tabela 5 , alguns moradores deixaram transparecer a revolta por transtornos ocorridos em relação à queda de energia, em dias de tempestades fortes. Ressalta-se ainda, a preocupação dos moradores para com seus vizinhos, pois as árvores os incomodam com sujeiras, levantamento de calçadas e encanamentos, o que faz prevalecer a cordialidade, entre os moradores, em evitar confusão com os vizinhos.

A calçada verde é uma prática ainda pouco explorada nas cidades, e pouco conhecida pelos moradores. Entre os $67,21 \%$ que disseram não ter benefícios (Tabela 3 ), $83,73 \%$ não comentaram nada e $11,45 \%$ opinaram que, com a calçada verde, a limpeza seria mais difícil, devido à sujeira de cachorro, visto que é um transtorno para os moradores lavar as calçadas constantemente (Tabela 6). 
Tabela 6 - Opinião dos moradores sobre calçada verde, nos bairros entrevistados de Americana/SP

\begin{tabular}{lll}
\hline Opinião & Quantidade & Porcentagem (\%) \\
\hline Não comentaram nada & 139 & 83,73 \\
Condiciona sujeira de cachorro & 19 & 11,45 \\
Dificulta manutenção (custo) & 6 & 3,61 \\
Atrai insetos & 2 & 1,20 \\
Total & 166 & 100 \\
\hline
\end{tabular}

O alto índice $(83,73 \%)$ de pessoas que não se manifestaram sobre a calçada verde, talvez não implique em rejeição, porém pode ser indicativo da ausência de instrução sobre os benefícios que ela pode fornecer.

Segundo Arnold (1992), a área sob copas de árvores não é adequada para plantio de grama, pela ausência de sol, além de haver competição das suas raízes com as raízes das árvores. Para Paiva e Gonçalves (2002), as gramíneas possuem denso sistema radicular em forma de cabeleira e são particularmente vantajosas para fixação da terra. Além disso, também aumentam a infiltração de água pela chuva.

Das 40 ruas selecionadas para o questionário, a maioria (65\%) apresentou calçadas com largura maior que 2 metros, o que propicia o plantio de árvores.

A prática de se plantar arbustos, com o intuito de aliviar as podas freqüentes, devido à fiação elétrica e aos danos em calçadas, ocasionados pelo afloramento de raízes das árvores, propagou-se de tal forma pelos órgãos ditos competentes, que faz-se necessários muitos esclarecimentos à população para se reverter este mito.

Nos bairros analisados, a resposta dos moradores em relação a este assunto não foi diferente, pois $57,49 \%$ de moradores responderam que gostam de arbustos, contra $29,55 \%$ que preferem árvores. Ainda, verificou-se que $8,91 \%$ das pessoas não têm opinião a respeito e 4,05\% não gostam de árvores nem arbustos (Tabela 7).

A preferência por plantio de arbustos gera um comodismo pelos órgãos públicos, pois, não buscam alternativas para reverter este quadro, tais como: mudança da fiação elétrica convencional pela compacta, ampliação do canteiro de plantio e aumento da largura das calçadas. 
Tabela 7 - Preferência dos moradores quanto ao tipo de vegetal arbóreo, nos bairros de Americana/SP

\begin{tabular}{lll}
\hline Descrição & Quantidade & Porcentagem (\%) \\
\hline Arbustos & 142 & 57,49 \\
Árvores & 73 & 29,55 \\
Tanto faz & 22 & 8,91 \\
Nenhuma & 10 & 4,05 \\
Total & 247 & 100 \\
\hline
\end{tabular}

A preferência dos moradores por plantas de floração significativa pode ser comprovada nas Tabelas 8 e 9, onde, na maioria das ruas, verificou-se a opção por espécies floríferas, destacando-se entre elas, a Stifftia crysantha Mikan e a Lagerstroemia indica $\mathrm{L}$.

Tabela 8 - Espécies oferecidas, mais votadas e o número de votos de cada uma, nas ruas de 800 a 1500m, em dois bairros de Americana/SP, evidenciando as de floração significativas $\left(^{*}\right)$

\begin{tabular}{|c|c|c|}
\hline Ruas de 800 a 1500 m & Espécie Oferecida & $\mathrm{N}^{\circ}$ votos \\
\hline & Lagerstroemia indica $L^{*}$ & 2 \\
\hline \multirow[t]{3}{*}{ Adelmar Tavares } & Cordia superba Cham * & - \\
\hline & Senna multijuga (Rich.) I. et B. * & 1 \\
\hline & Conofaryngea crassa Stapf. * & 2 \\
\hline \multirow[t]{3}{*}{ Álvaro Lins } & Senna macranthera (Collad.) I. et B. * & 1 \\
\hline & Gustavia augusta L. * & 2 \\
\hline & Lagerstroemia indica L. * & - \\
\hline \multirow[t]{3}{*}{ Aura Celeste } & Senna macranthera (Collad.) I. et B. * & 1 \\
\hline & Esenbeckia grandiflora Mart. * & - \\
\hline & Stifftia crysantha Mikan * & 2 \\
\hline \multirow[t]{3}{*}{ Cacilda Becker } & Dictyoloma vandellianum A. Juss. & - \\
\hline & Ilex paraguariensis St. Hil. & - \\
\hline & Guapira graciliflora (Mart. Ex. J. A. Schimidt) Lundel & - \\
\hline \multirow[t]{3}{*}{ Catulo Paixão } & Cordia superba Cham * & - \\
\hline & Trichilia hirta L. & - \\
\hline & Grevilea banksii R. Br. * & - \\
\hline \multirow[t]{2}{*}{ Cleomenes Campos } & Stifftia crysantha Mikan * & 1 \\
\hline & Ilex paraguariensis St. Hil. & - \\
\hline
\end{tabular}




\begin{tabular}{|c|c|c|}
\hline & Grevilea banksii R. Br. * & 1 \\
\hline \multirow[t]{3}{*}{ Clóvis Bruneli } & Cinammomum zeylanicum Ness. & - \\
\hline & Allophylus edulis (a . St. Hil.) & - \\
\hline & Guapira graciliflora (Mart. Ex. J. ㄹ Schimidt) Lundel & \\
\hline \multirow[t]{3}{*}{ Cornélio Pires } & Senna macranthera (Collad.) I. et B. * & 1 \\
\hline & Trichilia hirta L. & - \\
\hline & Stifftia crysantha Mikan * & - \\
\hline \multirow[t]{3}{*}{ Dalcídio Jurandir } & Gustavia augusta L. * & 1 \\
\hline & Eugenia involucrata D. C. & - \\
\hline & Senna multijuga (Rich.) I. et B. * & - \\
\hline \multirow[t]{3}{*}{ Guimarães Rosa } & Peschiera fuchsiaefolia Miers. * & 1 \\
\hline & Lagerstroemia indica $L^{*}$. & - \\
\hline & Lagerstroemia indica L. * & - \\
\hline \multirow[t]{3}{*}{ Lima Barreto } & Metrodorea nigra St. Hil. & 1 \\
\hline & Allophylus edulis (A. St. Hil.) & - \\
\hline & Gustavia augusta L. * & 2 \\
\hline \multirow[t]{3}{*}{ Maria Quitéria } & Ilex paraguariensis St. Hil. & - \\
\hline & Eugenia involucrata D. C. & 4 \\
\hline & Stifftia crysantha Mikan * & 3 \\
\hline \multirow[t]{3}{*}{ Mário de Andrade } & Guapira graciliflora (Mart. Ex. J. A. Schimidt) Lundel & 1 \\
\hline & Grevilea banksii R. Br. * & - \\
\hline & Ilex paraguariensis St. Hil. & - \\
\hline \multirow[t]{3}{*}{ Martins Pena } & Lagerstroemia indica L. * & 1 \\
\hline & Cordia superba Cham * & - \\
\hline & Metrodorea nigra St. Hil & 5 \\
\hline \multirow[t]{3}{*}{ Noel Rosa } & Allophylus edulis (A. St. Hil.) & - \\
\hline & Trichilia hirta L. & - \\
\hline & Alectryon tomentosum Radlk. & 3 \\
\hline \multirow[t]{2}{*}{ Raul Leoni } & Peschiera fuchsiaefolia Miers. * & 1 \\
\hline & Trichilia hirta L. & - \\
\hline
\end{tabular}


Tabela 9 - Espécies oferecidas, mais votadas e o número de votos de cada uma, nas ruas maiores que $1500 \mathrm{~m}$, em dois bairros de Americana/SP, evidenciando as de floração significativas $\left(^{*}\right)$

\begin{tabular}{|c|c|c|}
\hline Ruas maiores que $1500 \mathrm{~m}$ & Espécie Oferecida & $\mathbf{N}^{\circ}$ votos \\
\hline & Lagerstroemia indica $L^{*}$ & 2 \\
\hline \multirow[t]{4}{*}{ Aderaldo E. Araújo } & Cordia superba Cham * & - \\
\hline & Poecilanthe parviflora Benth & - \\
\hline & Neriun oleander L. * & - \\
\hline & Lagerstroemia indica L. * & 5 \\
\hline \multirow[t]{4}{*}{ Afonso Arinos } & Senna macranthera (Collad.) I. et B. * & 5 \\
\hline & Poecilanthe parviflora Benth. & 4 \\
\hline & Stifftia crysantha Mikan * & 4 \\
\hline & Casearia sylvestris SW. & 2 \\
\hline \multirow[t]{5}{*}{ Afonso Schimidt } & Eugenia involucrata D. C. & 4 \\
\hline & Cinammomum zeylanicum Ness. & 1 \\
\hline & Dictyoloma vandellianum A. Juss. & 3 \\
\hline & Licania tomentosa (Benth.) Fritsch. & 2 \\
\hline & Metrodorea nigra St. Hil. & 3 \\
\hline \multirow[t]{4}{*}{ Alcides Maya } & Ilex paraguariensis St. Hil. & - \\
\hline & Cinammomum camphora (L.) Ness Sebern. & 2 \\
\hline & Allophylus edulis (A. St. Hil.) & - \\
\hline & Lagerstroemia indica $\mathrm{L}^{*}$ & 1 \\
\hline \multirow[t]{4}{*}{ Anita Garibaldi } & Esenbeckia grandiflora Mart. * & - \\
\hline & Senna multijuga (Rich.) I. et B. * & - \\
\hline & Conofaryngia crassa Stapf * & 1 \\
\hline & Guapira graciliflora (Mart. Ex. J. A. Schimidt) Lundel & 6 \\
\hline \multirow[t]{4}{*}{ Antônio Conselheiro } & Maytenus ilicifolia Mart. Ex. Reiss. & - \\
\hline & Pittosporum undulatum Vent. & - \\
\hline & Alectryon tomentosum Radlk. & - \\
\hline & Lagerstroemia indica $\mathrm{L}^{*}$ & 4 \\
\hline \multirow[t]{4}{*}{ Ari Barroso } & Stifftia crysantha Mikan * & - \\
\hline & Cinammomum zeylanicum Ness. & - \\
\hline & Alectryon tomentosum Radlk. & - \\
\hline & Stifftia crysantha Mikan * & 1 \\
\hline \multirow[t]{4}{*}{ Benedito Calixtro } & Neriun oleander $\mathrm{L} .{ }^{*}$ & 2 \\
\hline & Metrodorea nigra St. Hil. & 2 \\
\hline & Trichilia hirta L. & - \\
\hline & Metrodorea nigra St. Hil. & 3 \\
\hline
\end{tabular}




\begin{tabular}{|c|c|c|}
\hline \multirow[t]{3}{*}{ Cândido Portinari } & Peschiera fuchsiaefolia Miers. * & 2 \\
\hline & Pittosporum undulatum Vent. & 2 \\
\hline & Allophylus edulis (A. St. Hil.) & 1 \\
\hline & Dictyoloma vandellianum A. Juss. & - \\
\hline \multirow[t]{2}{*}{ Cecília Meireles } & Stifftia crysantha Mikan * & - \\
\hline & Lagerstroemia indica $\mathrm{L}^{*}$ & - \\
\hline \multirow[t]{4}{*}{ Cruz e Souza } & Metrodorea nigra St. Hil. & - \\
\hline & Cordia superba Cham * & - \\
\hline & Alectryon tomentosum Radlk. & - \\
\hline & Grevilea banksii R. Br. * & 1 \\
\hline \multirow[t]{4}{*}{ Felipe Camarão } & Casearia sylvestris SW. & 3 \\
\hline & Poecilanthe parviflora Benth. & 1 \\
\hline & Cinammomum camphora (L.) Ness Sebern. & - \\
\hline & Lagerstroemia indica $\mathrm{L}$ * & - \\
\hline \multirow[t]{4}{*}{ Graciliano Ramos } & Senna macranthera (Collad.) I. et B * & - \\
\hline & Eugenia involucrata D. C. & - \\
\hline & Conofaryngea crassa Stapf. * & - \\
\hline & Guapira graciliflora (Mart. Ex. J. A. Schimidt) Lundel & - \\
\hline \multirow[t]{4}{*}{ José Conde } & Gustavia augusta L. * & 2 \\
\hline & Metrodorea nigra St. Hil. & 1 \\
\hline & Dictyoloma vandellianum A. Juss. & 1 \\
\hline & Lagerstroemia indica L. * & 4 \\
\hline \multirow[t]{4}{*}{ José Veríssimo } & Esenbeckia grandiflora Mart. & 1 \\
\hline & Dictyoloma vandellianum A. Juss. & 1 \\
\hline & Senna multijuga (Rich.) I. et B. * & 1 \\
\hline & Senna macranthera (Collad.) I. et B. * & 1 \\
\hline \multirow[t]{4}{*}{ Padre Cícero } & Ilex paraguariensis St. Hil. & - \\
\hline & Cordia superba Cham * & - \\
\hline & Poecilanthe parviflora Benth & 1 \\
\hline & Stifftia crysantha Mikan * & 3 \\
\hline \multirow[t]{4}{*}{ Maria C. Proença } & Eugenia involucrata D. C. & 1 \\
\hline & Alectryon tomentosum Radlk. & 1 \\
\hline & Allophylus edulis (A. St. Hil.) & 2 \\
\hline & Stifftia crysantha Mikan * & 1 \\
\hline \multirow[t]{4}{*}{ Osman Lins } & Neriun oleander L. * & 4 \\
\hline & Ilex paraguariensis St. Hil. & - \\
\hline & Metrodorea nigra St. Hil. & - \\
\hline & Cinammomum zeylanicum Ness. & - \\
\hline \multirow[t]{2}{*}{ Tobias Barreto } & Conofaryngea crassa Stapf. * & - \\
\hline & Neriun oleander L. * & - \\
\hline
\end{tabular}




\begin{tabular}{lll}
\hline & Lagerstroemia indica L. ${ }^{*}$ & 1 \\
\hline \multirow{2}{*}{ Ricardo Gonçalves } & Casearia sylvestris SW. & - \\
& Gustavia augusta L. ${ }^{*}$ & 1 \\
& Dictyoloma vandellianum A. Juss. & - \\
& Cinammomum camphora (L.) Ness Sebern. & - \\
\hline \multirow{2}{*}{ Valdomiro Siqueira } & Grevilea banksii R. Br. ${ }^{*}$ & 1 \\
& Stifftia crysantha Mikan * & 3 \\
& Casearia sylvestris SW. & - \\
\hline \multirow{2}{*}{ Vitalino } & Poecilanthe parviflora Benth & - \\
\hline \multirow{3}{*}{ Xico Santeiro } & Cinammomum zeylanicum Ness. & - \\
& Gustavia augusta L. * & - \\
\hline & Guapira graciliflora (Mart. Ex. J. A. Schimidt) Lundel & 1 \\
& Stifftia crysantha Mikan * & 2 \\
& Dictyoloma vandellianum A. Juss. & 1 \\
& Alectryon tomentosum Radlk. & - \\
\hline
\end{tabular}

A escolha por árvores com flores pelos moradores foi em virtude do reduzido número de espécies floríferas existentes com flores significativas o bastante para tornar o ambiente mais agradável.

As espécies frutíferas comestíveis foram bem procuradas pelos moradores; no entanto, apenas a frutífera Eugenia involucrata, que constava na lista de espécies indicadas, foi a mais votada. Alguns moradores ressaltaram as inconveniências do plantio de frutíferas, entre eles, a atração dos pássaros, que trariam sujeira através das fezes, e o convívio com morcegos. $\mathrm{Na}$ indicação por espécies frutíferas, deve-se priorizar frutos de tamanhos reduzidos e não carnosos, para evitar acidentes com carros e pessoas.

\section{CONCLUSÃO}

A maioria da população consultada não deseja, plantar árvores nas calçadas por causa das preocupações com podas, fiação elétrica e danos em calçadas, e aquelas que dispõem a plantar, têm preferência por arbustos.

As espécies floríferas, como a Stifftia crysantha Mikan e a Lagerstroemia indica L., foram as escolhidas pelos moradores.

Embora tenha havido uma manifestação negativa dos munícipes em relação à arborização viária, na cidade de Americana, essa participação das pessoas contribuiu para aumentar a qualidade da pesquisa, bem como seus resultados práticos, o que demonstra que a comunidade é fonte de hábitos e costumes que, talvez, devam ser enfocados, num 
primeiro momento, para obter o sucesso desejado como promotores do desenvolvimento sustentável da arborização viária.

\section{AGRADECIMENTOS}

Os autores agradecem ao Conselho Nacional d Desenvolvimento Científico e Tecnológico - CNPq, que contribuiu com apoio financeiro para realização deste trabalho

\section{REFERÊNCIAS BIBLIOGRÁFICAS}

ARNOLD, H. F. Trees in urban design. 2. ed. New York: Van Nostrand Reinhold, 1993. $188 p$.

KONIJNENDIJK, C. C. Adapting forestry to urban demands - role of comunication in urban forestry in Europe. Landscape and Urban Planning, Amsterdam, v.52, p. 89-100, 2000.

KUCHELMEISTER,G.; BRAATZ, S. Urban forestry revisited. Unasylva, Rome, v. 44, n. 173, p. 3-12, 1993.

LORENZI, H. Árvores Brasileiras: manual de identificação e cultivo de plantas arbóreas nativas do Brasil. Nova Odessa: Editora Plantarum, 1992. v. 1, 352 p.

LORENZI, H. Árvores Brasileiras: manual de identificação e cultivo de plantas arbóreas nativas do Brasil. Nova Odessa: Editora Plantarum, 1998. v. 2, 352 p.

LORENZI, H. et al. Plantas exóticas no Brasil: madeiras, ornamentais e aromáticas. 2.ed. Nova Odessa: Editora Plantarum, 2003. v .1, 368p.

MILANO, M. S.; DALCIN, E. C. Arborização de vias públicas. Rio de Janeiro: Light, 2000. $226 \mathrm{p}$.

PAIVA, H. N.; GONÇALVES, W. Florestas urbanas: planejamento para melhoria da qualidade de vida. Viçosa/MG: Aprenda Fácil, 2002. 180p.(Série Arborização Urbana,2). 